\title{
Germinação de pólen e aplicação de ácido bórico em botões florais de nespereiras
}

\author{
Paulyene Vieira Nogueira ('); Daniel Fernandes da Silva ('); Rafael Pio (2*); \\ Pedro Augusto de Oliveira Silva (2); Rayane Barcelos Bisi (2); Rodrigo Vieira Balbi (2) \\ (') Universidade Federal de Lavras (UFLA), Departamento de Biologia, Caixa Postal 3037, 37200-000 Lavras (MG), Brasil. \\ (2) UFLA, Departamento de Agricultura, 37200-000 Lavras (MG), Brasil. \\ (*) Autor correspondente: rafaelpio@hotmail.com
}

Recebido: 12/ago./2014; Aceito: 3/nov./2014

\begin{abstract}
Resumo
O objetivo do trabalho foi estabelecer meio de cultura e avaliar a germinação de grãos de pólen in vitro e após a aplicação de boro na panícula em cultivares de nespereira. Foi determinado o meio de cultura ideal para germinação dos grãos de pólen e avaliada a porcentagem de germinação utilizando pólen da cultivar Mizauto. Também avaliou-se o melhor estágio de desenvolvimento floral e horário do dia para coleta do pólen, bem como o tempo de incubação para sua germinação. Após estabelecido o meio, foi determinada a germinação de nove cultivares: Mizauto, Mizuho, Fukuhara, Parmogi, Centenária, Kurisaki, Néctar de Cristal, Mizumo e Precoce de Campinas. Em campo, avaliou-se a aplicação de ácido bórico em panículas de nespereiras Mizauto, nas concentrações $600 \mathrm{mg} \mathrm{L}^{-1}, 1.200 \mathrm{mg} \mathrm{L}^{-1}$ e $1.800 \mathrm{mg} \mathrm{L}^{-1}$, além do controle sem aplicação. $\mathrm{O}$ meio de cultura estabelecido foi de $200 \mathrm{~g} \mathrm{~L}^{-1}$ de sacarose, $1.200 \mathrm{mg} \mathrm{L}^{-1}$ de ácido bórico, solidificado com $10 \mathrm{~g} \mathrm{~L}^{-1}$ de agar e pH 6, incubado por sete horas. 0 melhor estágio do botão floral foi na pré-antese, coletado entre 14 e 18 horas. A aplicação de $900 \mathrm{mg} \mathrm{L}^{-1}$ de ácido bórico em campo elevou a germinação dos grãos de pólen para 57,68\%.
\end{abstract}

Palavras-chave: Eriobotrya japonica Lindl., melhoramento genético, viabilidade de pólen.

\section{Pollen germination and boric acid applying in loquat flower buds}

\begin{abstract}
This study aimed to establish a culture media and evaluate pollen grains germination in vitro and after boron applying in the panicles of Loquat cultivars. Was established an appropriate culture media for pollen grains germination and evaluated the germination percentage in Mizauto cultivar. Was also evaluated the best stage of floral growth and the best period of the day to collect the pollen, beyond the evaluation of incubation time for their germination. After established the appropriate culture media, it was determined the germination of 9 cultivars: Mizauto, Mizuho, Fukuhara, Parmogi, Centenária, Kurisaki, Néctar de Cristal, Mizumo and Precoce de Campinas. On the field, was evaluated the applying of boric acid with different concentrations 600, 1200 and $1800 \mathrm{mg} \mathrm{L}^{-1}$ and without applying on the panicles of Mizauto cultivar. The culture media established was composed by $200 \mathrm{~g} \mathrm{~L}^{-1}$ of sucrose, $1200 \mathrm{mg} \mathrm{L}^{-1}$ of boric acid, solidified with $10 \mathrm{~g} \mathrm{~L}^{-1}$ of Agar and pH 6, and incubated during seven hours. The best stage of floral bud was in pre-anthesis, collected between two and six pm. The applying of $900 \mathrm{mg} \mathrm{L}^{-1}$ of boric acid on field raised the pollen grain germination to $57.68 \%$.
\end{abstract}

Key words: Eriobotrya japonica Lindl., breeding programs, pollen viability.

\section{INTRODUÇÃO}

O aumento do consumo de nêsperas está relacionado principalmente ao sabor peculiar dos seus frutos, bem como às suas características nutriterapêuticas. As nêsperas são ricas em ácido galacturônico, málico e fumárico, flavonoides, carotenoides e outros compostos antioxidantes, localizados na casca e na polpa dos frutos (Faria et al., 2009; Ferreres et al., 2009). Além disso, possui elevada concentração de pectina, o que vem a favorecer

o processamento industrial na fabricação de doces e geleias, atividade ainda não explorada comercialmente (Hasegawa et al., 2010).

No Brasil, a nespereira é uma excelente opção de cultivo para a diversificação de propriedades rurais, principalmente na época de maturação de seus frutos, que se concentra entre os meses de julho e setembro, quando há escassez de outras frutas no mercado (Grassi et al., 2011). 
Apesar de a nespereira possuir algumas vantagens de cultivo em relaçáo a outras frutíferas, a lucratividade ainda é baixa, devido a problemas relacionados ao desempenho produtivo das cultivares (Pio et al., 2007). A disponibilização de novas seleçóes avançadas é primordial para o cultivo em São Paulo, principalmente no que tange aos incrementos produtivos, para assim se elevar a renda em unidades produtoras dessa frutífera (Bettiol et al., 2010).

Em vista do exposto, nota-se que há necessidade de se intensificar o programa de melhoramento genético de nespereira no Brasil, voltado para a seleção de cultivares altamente produtivas e aptas a serem cultivadas principalmente em São Paulo, maior produtor nacional. Buscando dar suporte aos programas de melhoramento genético, o conhecimento das características florais no germoplasma disponível, tais como a viabilidade e a capacidade germinativa do pólen, é de grande importância para a seleção dos progenitores a serem utilizados nas hibridaçóes. A análise da fertilidade dos grãos de pólen dos progenitores coletados a campo é condição preliminar indispensável para os cruzamentos (Chagas et al., 2010).

$\mathrm{Na}$ natureza, a única maneira de verificar a viabilidade dos grãos de pólen é por meio da realizaçáo de cruzamentos a campo e posterior avaliação da frutificaçáo. Porém esse processo é oneroso e demorado. Uma alternativa mais rápida é a utilização de testes de germinação in vitro dos grãos de pólen. Existe uma relação entre a porcentagem de germinação e a viabilidade do pólen (Bolat \& Pirlak, 1999).

Sabe-se que vários compostos orgânicos e inorgânicos interferem na germinação in vitro, dos quais o cálcio e o boro são os mais importantes (Chagas et al., 2010). Figueiredo et al. (2013) ressaltaram que o ácido bórico é fundamental na germinação dos grãos de pólen de cultivares de amoreira-preta e Nava et al. (2009), que a aplicaçáo de boro no período de floração aumentou a fixação e produção dos frutos de pessegueiro. Assim, caso o ácido bórico influencie na germinação de grãos de pólen in vitro da nespereira, a aplicaçấo desse elemento nas panículas pode aumentar o número de sementes e a fixação de frutos, influenciando no aumento da massa unitária e no aumento da produção das nespereiras.

Os objetivos do presente trabalho foram: ajustar os componentes básicos do meio de cultura para verificar a capacidade germinativa dos grãos de pólen de cultivares de nespereira, quantificar o número de grãos de pólen por antera e por flor e, ainda, verificar a influência da pulverização de boro nas panículas sobre a germinação de grãos de pólen.

\section{MATERIAL E MÉTODO}

O trabalho foi realizado entre os meses de janeiro e maio de 2014 e foi dividido em três etapas:

\section{Definição do meio de cultura e análise da germinação}

Primeiramente foi feita a determinação do meio de cultura básico para a otimização da germinação dos grãos de pólen da nespereira. Foram retiradas as anteras de dez botôes florais da cultivar Mizauto coletados no final da tarde, utilizando-se de uma pinça. As anteras foram armazenadas em placas de Petri destampadas à temperatura controlada $\left(27^{\circ} \mathrm{C}\right)$ por 12 horas na ausência de luz, para que ocorresse a antese, completa deiscência e liberação dos grãos de pólen (Ramos et al., 2008).

Após a coleta dos grãos de pólen, foram realizadas as seguintes etapas do experimento:

1) Concentraçôes de ágar ( $4 \mathrm{~g} \mathrm{~L}^{-1}, 6 \mathrm{~g} \mathrm{~L}^{-1}, 8 \mathrm{~g} \mathrm{~L}^{-1} \mathrm{e}$ $\left.10 \mathrm{~g} \mathrm{~L}^{-1}\right)$ e $\mathrm{pH}$ do meio: 4, 5, 6 e 7;

2) Concentraçôes de sacarose $\left(0 \mathrm{~g} \mathrm{~L}^{-1}, 25 \mathrm{~g} \mathrm{~L}^{-1}, 50 \mathrm{~g} \mathrm{~L}^{-1}\right.$, $75 \mathrm{~g} \mathrm{~L}^{-1}, 100 \mathrm{~g} \mathrm{~L}^{-1}, 125 \mathrm{~g} \mathrm{~L}^{-1}, 150 \mathrm{~g} \mathrm{~L}^{-1}, 175 \mathrm{~g} \mathrm{~L}^{-1}$ e $\left.200 \mathrm{~g} \mathrm{~L}^{-1}\right)$;

3) Concentraçóes de nitrato de cálcio $-\mathrm{Ca}\left(\mathrm{NO}_{3}\right)_{2}$ (0 mg L ${ }^{-1}, 200 \mathrm{mg} \mathrm{L}^{-1}, 400 \mathrm{mg} \mathrm{L}^{-1}$ e $\left.800 \mathrm{mg} \mathrm{L}^{-1}\right)$;

4) Concentraçôes de ácido bórico $-\mathrm{H}_{3} \mathrm{BO}_{3}\left(0 \mathrm{mg} \mathrm{L}^{-1}\right.$, $400 \mathrm{mg} \mathrm{L}^{-1}, 800 \mathrm{mg} \mathrm{L}^{-1}$ e $1.200 \mathrm{mg} \mathrm{L}^{-1}$ );

5) Tempo de emissão do tubo polínico (germinação): $0,1,2,3,4,5,6$ e 7 horas após inoculação.

A determinação do meio de cultura foi realizada de maneira seqüencial (etapas 1 a 5), sempre utilizando o melhor resultado do experimento anterior para a montagem dos tratamentos subsequentes, conforme Figueiredo et al. (2013).

Após determinar o melhor meio de cultura e tempo de incubação para germinação do pólen (emissão do tubo polínico), foi determinado o estágio de coleta do pólen e a hora de coleta:

1) Estágio de desenvolvimento floral para coleta das anteras: botáo totalmente fechado, pré-antese (botão ainda fechado e com as pétalas evidentes) e antese (flor completamente aberta);

2) Horário de coleta dos botôes: botóes florais coletados às $6,10,14$ e 18 horas do dia.

O meio foi incubado em laboratório sob condiçóes controladas (temperatura média de $27^{\circ} \mathrm{C}$ ), de acordo com metodologia descrita em Chagas et al. (2010) e Figueiredo et al. (2013). Para cada teste, o pólen foi distribuído, por meio de um pincel, sobre a superfície das placas de Petri contendo $20 \mathrm{~mL}$ de meio de cultura, de modo a promover uma distribuição homogênea. Após aproximadamente seis horas de incubação, com exceção do experimento de diferentes períodos de emissão do tubo polínico, foram contados, com auxílio de lupa monocular com objetiva de 10x, os grãos de pólen germinados ou não. Foram considerados germinados os grãos de pólen cujo comprimento do tubo polínico 
ultrapassou o dobro do próprio diâmetro (Figueiredo et al., 2013).

Esses experimentos foram conduzidos em delineamento inteiramente casualizado, com quatro repetiçóes, sendo cada repetição um quadrante da placa de Petri e cada repetição constituída pela média de oito campos de visão.

Após o estabelecimento do meio de cultura básico para a germinação do pólen da nespereira e a determinação do tempo de emissão do tubo polínico, estágio de desenvolvimento floral para coleta das anteras e horário de coleta dos botôes, os grãos de pólen de nove cultivares de nespereira foram submetidos à germinação in vitro, para avaliação de sua capacidade de germinação. As cultivares utilizadas foram: Mizauto, Mizuho, Fukuhara, Parmogi, Centenária, Kurisaki, Néctar de Cristal, Mizumo e Precoce de Campinas. Os botôes florais foram coletados na coleção de nespereira do Núcleo de Produção de Mudas de São Bento do Sapucaí, SP, da Coordenadoria de Assistência Técnica Integral (Cati) e o experimento foi realizado na Universidade Federal de Lavras.

Esse experimento foi conduzido em delineamento inteiramente casualizado, composto por nove tratamentos, representados pelas cultivares de nespereira, com quatro repetiçóes, sendo cada repetição um quadrante da placa de Petri e cada repetiçấo constituída pela média de oito campos de visão.

\section{Verificação do número de grãos de pólen por antera e por flor}

Para o experimento de contagem do número de grãos de pólen por antera e por flor foram coletados seis botóes florais no estágio pré-antese de cada cultivar, sendo contado o número de anteras por flor. Em seguida separaram-se cinco anteras de forma aleatória e cada conjunto de anteras foi entáo armazenado em tubos Eppendorf destampados à temperatura controlada $\left(27^{\circ} \mathrm{C}\right)$ por 24 horas, na ausência de luz, para ocorrência da deiscência e, assim, da liberação dos grãos de pólen (Ramos et al., 2008). Passada 24 horas foi acrescentada aos tubos uma solução de $1.000 \mu \mathrm{l}$ de ácido láctico. Após 48 horas, uma amostra de $10 \mu \mathrm{l}$ de cada Eppendorf foi colocada em uma lâmina de leitura (Neubauer) para a realização da contagem do número de grãos de pólen, com auxílio de microscópio óptico (objetiva de 100x). Esse experimento foi conduzido com cinco repetiçóes, sendo cada repetição constituída por oito leituras na lâmina de Neubauer.

A quantidade de gráos de pólen por antera foi calculada multiplicando-se a média do número de grãos de pólen de cada amostra pelo volume do ácido láctico da solução $(1.000 \mu \mathrm{l})$ e dividindo-se esse valor pelo produto entre o volume de ácido láctico da amostra $(10 \mu \mathrm{l})$ e o número de anteras de cada tubo (cinco). O número de grãos de pólen por flor foi calculado pela multiplicação da estimativa média de grãos de pólen por antera pelo número médio de anteras por flor.

\section{Pulverização das panículas com ácido bórico}

Para o experimento em campo com ácido bórico foram selecionadas e identificadas panículas em estágio inicial de desenvolvimento dos botôes florais. O experimento consistiu na aplicação de quatro concentraçôes de ácido bórico diretamente nas panículas: $600 \mathrm{mg} \mathrm{L}^{-1}, 1.200 \mathrm{mg} \mathrm{L}^{-1}$ e $1.800 \mathrm{mg} \mathrm{L}^{-1}$, além do controle sem aplicação. Após o completo desenvolvimento dos botóes florais foi avaliada a viabilidade polínica dos grãos de pólen oriundos das panículas pulverizadas com as diferentes concentraçóes de ácido bórico. Os botôes florais foram removidos no estágio pré-antese, entre as 14 e as 18 horas. O pólen foi distribuído, por meio de um pincel, sobre a superfície das placas de Petri contendo $20 \mathrm{~mL}$ do meio de cultura previamente estabelecido. O delineamento estatístico foi inteiramente casualizado, com quatro repetiçóes, sendo cada repetição um quadrante da placa de Petri e cada repetiçáo constituída pela média de oito campos de visão.

Os dados obtidos foram submetidos à análise de variância, sendo as médias quantitativas submetidas à regressão linear ou quadrática, ao nível de $5 \%$ de probabilidade, e as médias qualitativas avaliadas pelo teste de comparação de médias Scott-Knott. As análises foram realizadas pelo Programa Computacional Sistema para Análise de Variância - SISVAR (Ferreira, 2011).

\section{RESULTADOS E DISCUSSÃO}

\section{Definição do meio de cultura e análise da germinação}

Quanto ao experimento realizado para estabelecer um protocolo adequado de meio de cultura para a germinação dos grãos de pólen, observou-se que o menor $\mathrm{pH}$ desfavoreceu a germinação. Em pH 5 se obteve apenas 4,64\% de germinação em meio solidificado com $8 \mathrm{~g} \mathrm{~L}^{-1}$ de ágar (Figura 1a). Ramos et al. (2008) afirmam que ocorre aumento na germinação de grãos de pólen, em citros, com o aumento do $\mathrm{pH}$ no meio de cultivo.

Quando se aferiu $\mathrm{pH}$ 6, houve aumento linear da porcentagem de geminaçáo à medida que se se aumentou a concentração de ágar, chegando-se a obter $17,88 \%$ de germinação com a adição de $10 \mathrm{~g} \mathrm{~L}^{-1}$ de ágar. Uma possível explicação para a porcentagem de germinação mais alta ter ocorrido na concentração de $10 \mathrm{~g} \mathrm{~L}^{-1}$ de ágar é que a alta concentraçáo desse agente solidificante possibilitou uma maior consistência do meio de cultura, o que promoveu o equilíbrio do potencial osmótico do meio e, assim, favoreceu a germinação dos grãos de pólen. É um fator importante para o meio de cultura que o $\mathrm{pH}$ seja aferido adequadamente, 
pois ele influencia diretamente na solidificação do meio (Chagas et al., 2009).

Com relação à adição de sacarose ao meio de cultura, ocorreu aumento linear à medida que se aumentou a concentração ao meio básico, chegando a ser registrado $46,6 \%$ de germinação com a concentração de $200 \mathrm{~g} \mathrm{~L}^{-1}$ de sacarose (Figura 1b). Aumento linear na porcentagem de germinação dos grãos de pólen à medida que se elevou a concentração de sacarose também foi constado por Chagas et al. (2010) em trabalhos realizados com pereira (Pyrus spp.) e de Figueiredo et al. (2013) em trabalhos com amoreira-preta (Rubus ssp.). Segundo esses autores, o efeito da adição de sacarose na germinação de grãos de pólen deve estar relacionado com o fornecimento de energia metabólica e esqueletos carbônicos para a biossíntese de compostos orgânicos necessários para o crescimento das células.
O mesmo não ocorreu com a adição de nitrato de cálcio ao meio, ocorrendo decréscimo linear da germinaçáo à medida que se aumentou a concentração de nitrato de cálcio no meio (Figura 1c), corroborando resultados obtidos por Figueiredo et al. (2013). Porém, o ácido bórico foi fundamental para o estímulo da germinação dos grãos de pólen, obtendo-se $55,15 \%$ de germinação com a concentração de $1.200 \mathrm{mg} \mathrm{L}^{-1}$ de ácido bórico (Figura 1d), incremento de 15,74\% em relação à ausência desse elemento ao meio de cultura. $\mathrm{O}$ boro na presença de sacarose forma o complexo ionizável sacaroseborato, o qual reage mais rapidamente com as membranas celulares, facilitando o desenvolvimento in vitro. A adição de boro também foi benéfica na germinaçáo dos grãos de pólen de pereira (Chagas et al., 2010) e amoreira-preta (Figueiredo et al., 2013). Os resultados demonstram que apenas a presença do boro foi satisfatória para a germinação
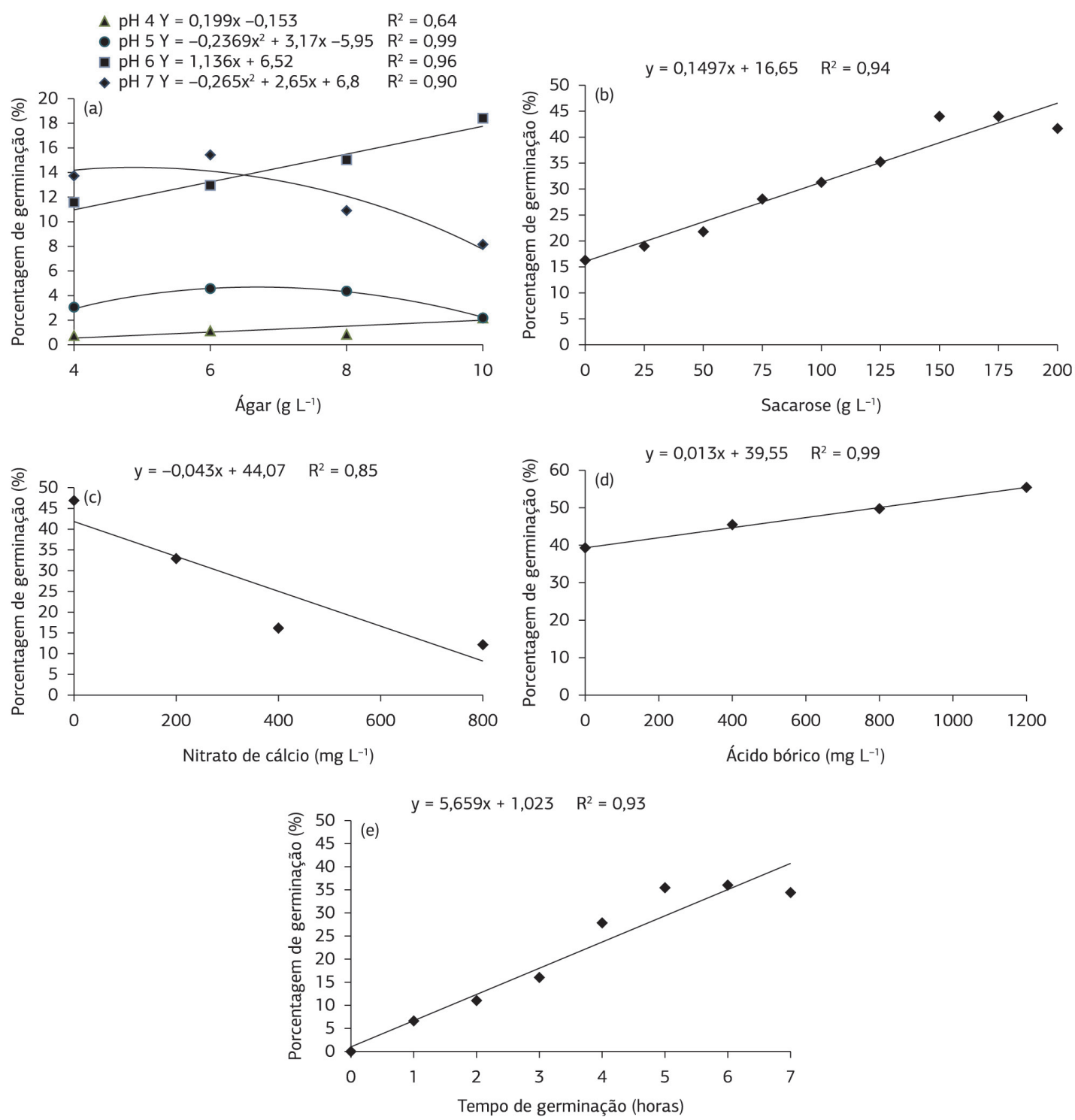

Figura 1. Porcentagem de germinação in vitro de grãos de pólen da nespereira Mizauto submetidos a diferentes pH e concentraçôes de agar $\left(\mathrm{g} \mathrm{L}^{-1}\right)$ no meio de cultura (a), diferentes concentraçôes de sacarose $\left(\mathrm{g} \mathrm{L}^{-1}\right)(\mathrm{b})$, diferentes concentraçóes de nitrato de cálcio (mg $\left.\mathrm{L}^{-1}\right)$ (c), diferentes concentraçóes de ácido bórico $\left(\mathrm{mg} \mathrm{L}^{-1}\right)(\mathrm{d})$ e diferentes tempos de incubação para germinação do grão de pólen (e). 
de grãos pólen. De acordo com Franzon \& Raseira (2006), o boro estimula o crescimento do tubo polínico e diminui a probabilidade de o pólen se romper.

Quando avaliado o tempo de emissão do tubo polínico, pôde-se observar que a germinaçáo dos grãos de pólen teve início após uma hora da inoculaçáo no meio, concordando com os resultados obtidos em pereira por Chagas et al. (2010). Houve aumento na porcentagem de grãos de pólen que emitiram tubo polínico até sete horas pós-inoculação (40,63\% de germinação) (Figura 1e). Segundo Gaaliche et al. (2013) e Zambon et al. (2014), há aumento na porcentagem de germinação dos grãos de pólen no decorrer do tempo de incubação.

Quanto ao estágio de desenvolvimento floral para coleta das anteras, não houve diferença entre a germinação dos grãos de pólen oriundos de botóes nos estágios pré-antese e antese, que se sobressaíram em relação à germinação dos grãos de pólen coletados de botôes totalmente fechados (Figura 2a). Recomenda-se coletar botôes na fase de préantese, para evitar contaminação varietal devida à presença dos agentes polinizadores. Quanto ao horário de coleta dos botôes, quando esses foram extraídos das plantas entre as 14 e 18 horas do dia houve maior germinação dos grãos de pólen (Figura 2b). Segundo Bonaventure (1999) a melhor germinação de grãos de pólen está associada principalmente à umidade relativa do ar e à temperatura, sendo que a melhor germinação de grãos de pólen de muitas espécies costuma ocorrer nas primeiras horas da manhá, contudo variaçôes podem ocorrer conforme o grau de tolerância do grão de pólen à dessecaçáo. Segundo Oliveira et al. (2012), o ambiente também influencia o horário de maior intensidade de voos das abelhas, com maior intensidade nas horas mais quentes do inverno e primavera.

Franchi et al. (2011) classificaram como ortodoxos grãos de pólen com maior capacidade de resistência ao ambiente, como os verificados em nespereira. Dessa forma, os grãos de pólen da espécie podem apresentar maior viabilidade nesse período, atuando como estratégia ecológica da espécie.

Botóes florais coletados na fase da pré-antese entre as 14 e 18 horas do dia cujos grãos de pólen foram colocados para germinação no meio de cultura acrescido de $200 \mathrm{~g} \mathrm{~L}^{-1}$ de sacarose e $1.200 \mathrm{mg} \mathrm{L}^{-1}$ de ácido bórico, com $\mathrm{pH}$ aferido para 6 e meio e solidificado com $10 \mathrm{~g} \mathrm{~L}^{-1}$ de ágar diferiram entre as cultivares de nespereira estudadas. A maior porcentagem de germinação foi observada com a cultivar Mizauto (51,74\%), seguida das cultivares Mizuho, Parmogi, Centenária e Kurisaki (Tabela 1). As demais cultivares apresentaram menor germinação dos grãos de pólen. Sharafi et al. (2011) também verificaram diferença na capacidade de germinação entre cultivares de nespereira.
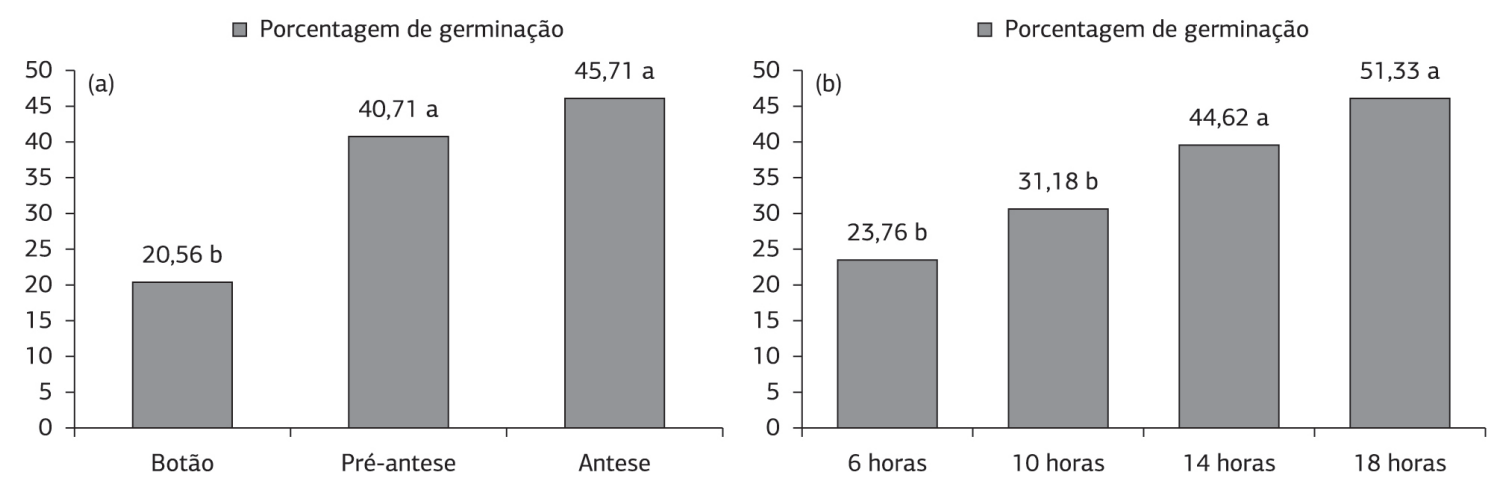

Figura 2. Estágio de desenvolvimento floral para coleta dos grãos de pólen (a) e horário de coleta dos botôes para a germinação do grão de pólen (b) da nespereira Mizauto.

Tabela 1. Porcentagem de germinação média, número de anteras por flor, número de grãos de pólen por antera e por flor em diferentes cultivares de nespereira

\begin{tabular}{lcccc} 
Cultivares & $\begin{array}{c}\text { Porcentagem de } \\
\text { germinação (\%) }\end{array}$ & $\begin{array}{c}\text { Número de anteras } \\
\text { por flor }\end{array}$ & $\begin{array}{c}\text { Número de pólen } \\
\text { por antera }\end{array}$ & $\begin{array}{c}\text { Número de pólen } \\
\text { por flor }\end{array}$ \\
\hline Mizauto & $51,74 \mathrm{a}$ & $18,67 \mathrm{~ns}$ & $1.448,00 \mathrm{a}$ & $27.228,00 \mathrm{a}$ \\
\hline Mizuho & $43,38 \mathrm{~b}$ & 20,67 & $1.058,33 \mathrm{c}$ & $22.024,34 \mathrm{c}$ \\
\hline Fukuhara & $25,19 \mathrm{c}$ & 20,33 & $943,00 \mathrm{~d}$ & $19.055,00 \mathrm{~d}$ \\
\hline Parmogi & $41,51 \mathrm{~b}$ & 20,67 & $933,00 \mathrm{~d}$ & $19.040,00 \mathrm{~d}$ \\
\hline Centenária & $37,98 \mathrm{~b}$ & 22,00 & $1.273,00 \mathrm{~b}$ & $27.504,00 \mathrm{a}$ \\
\hline Kurisaki & $39,19 \mathrm{~b}$ & 20,83 & $1.121,00 \mathrm{C}$ & $23.094,00 \mathrm{~b}$ \\
\hline Néctar de Cristal & $29,51 \mathrm{c}$ & 21,17 & $1.143,34 \mathrm{c}$ & $23.781,34 \mathrm{~b}$ \\
\hline Mizumo & $23,71 \mathrm{c}$ & 21,00 & $1.255,34 \mathrm{~b}$ & $26.480,00 \mathrm{a}$ \\
\hline Precoce de Campinas & $18,55 \mathrm{c}$ & 20,33 & $884,00 \mathrm{~d}$ & $18.020,00 \mathrm{~d}$ \\
\hline C.V. (\%) & 22,71 & 4,88 & 12,41 & 11,06 \\
\hline
\end{tabular}

(1) Médias seguidas pela mesma letra não diferem entre si pelo teste Scott-Knott ( $\mathrm{x} \leq 0,05)$; ns - não significativo. 


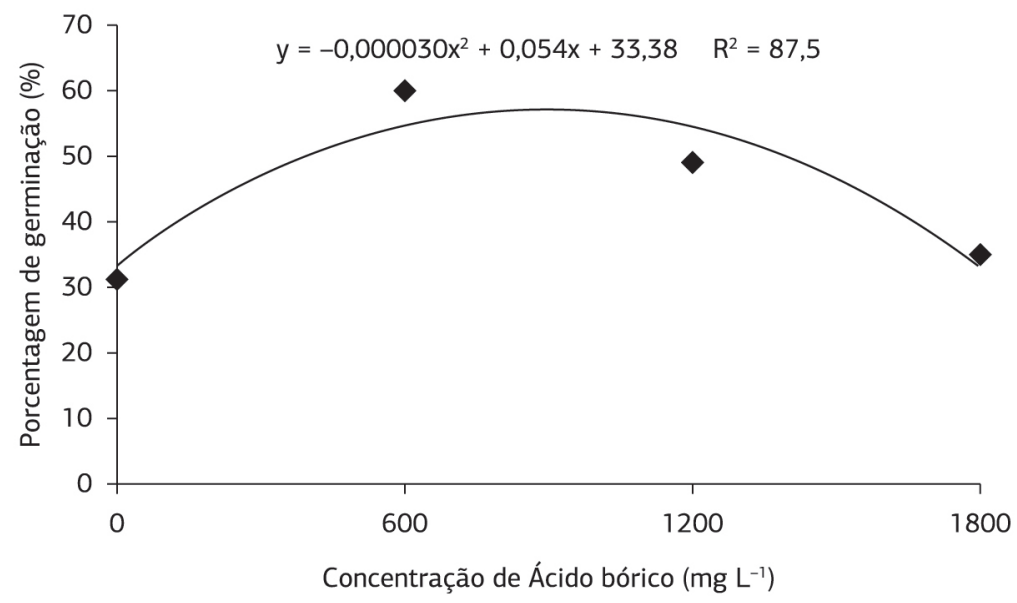

Figura 3. Porcentagem de germinação de grãos de pólen da nespereira Mizauto em cachos florais (panículas) pulverizados com diferentes concentrações de ácido bórico.

\section{Verificação do número de grãos de pólen por antera e por flor}

Não houve diferença entre o número de anteras por flor entre as cultivares (Tabela 1). Outros trabalhos com frutíferas da família Rosaceae demonstraram que o número de estames por flor pode apresentar variação entre diferentes cultivares. Contudo, um maior número de anteras não é indicativo de uma maior quantidade de pólen por flor (Albuquerque et al., 2010). No presente trabalho, o número de pólen por antera variou significativamente entre as cultivares, sendo que a cultivar Mizauto apresentou maior valor (Tabela 1), mas menor número de anteras, apesar de não ter ocorrido diferença estatística entre as demais cultivares. As cultivares Mizauto, Centenária e Mizumo apresentaram maior número de pólen por flor e a Mizuho, a menor quantidade, 5.479,66 a menos em relação à cultivar Centenária (Tabela 1).

Segundo Gaaliche et al. (2011), o número de grãos de pólen por antera e por flor pode influenciar no aumento da produção.

\section{Pulverização das panículas com ácido bórico}

Devido ao elemento boro ter promovido melhorias na germinação dos gráos de pólen, conforme apresentado na figura $1 \mathrm{~d}$, aplicaram-se as diferentes concentraçōes de ácido bórico. Pelo desdobramento da equação de segundo grau, a concentração de $900 \mathrm{mg} \mathrm{L}^{-1}$ de ácido bórico aplicada nas panículas quando os botôes estavam no estágio inicial do desenvolvimento propiciou $57,68 \%$ de germinação dos grãos de pólen (Figura 3), acréscimo de 24,3\% em relação a não pulverização com ácido bórico. Segundo Nava et al. (2009), a aplicação de boro no período de floração aumentou a fixação e produçấo dos frutos de pessegueiro.
Esse crescimento da germinação dos grãos de pólen pode ser significativo no aumento da fixação dos frutos e também no aumento de sua massa unitária, o que poderá elevar os índices produtivos das nespereiras brasileiras relatados por Bettiol et al. (2010) e Pio et al. (2007).

\section{CONCLUSÃO}

O protocolo de meio de cultura para germinação de grãos de pólen de nespereira é $200 \mathrm{~g} \mathrm{~L}^{-1}$ de sacarose e $1.200 \mathrm{mg} \mathrm{L}^{-1}$ de ácido bórico solidificado com $10 \mathrm{~g} \mathrm{~L}^{-1}$ de agar e $\mathrm{pH}$ aferido para 6 e deve ser avaliado com sete horas de incubação;

Os botóes florais devem ser coletados em estágio de pré-antese entre 14 e 18 horas;

O número de grãos de pólen por antera e por flor varia entre os cultivares de nespereira;

A aplicação de $900 \mathrm{mg} \mathrm{L}^{-1}$ de ácido bórico em panículas de nespereira Mizauto proporciona aumento na germinação de grãos de pólen.

\section{REFERÊNCIAS}

Albuquerque, C.L. Jr., Denardi, F., Dantas, A. C. M., \& Nodari, R. O. (2010). Número de anteras por flor, grãos de pólen por antera e capacidade germinativa do pólen de diferentes cultivares de macieiras. Revista Brasileira de Fruticultura, 32, 1255-1260. http://dx.doi. org/10.1590/S0100-29452010005000129.

Bettiol, J. E., No., Campo Dall'Orto, F. A., Barbosa, W., Chagas, E. A., Pio, R., \& Costa, F. C. (2010). Potencial produtivo de novas seleções de nespereira. Ciência Rural, 40, 1277-1282. http://dx.doi. org/10.1590/S0103-84782014000600031.

Bolat, Y., \& Pirlak, L. (1999). An investigation on pollen viability, germination and tube growth in some stone fruits. Turkish Journal of Agriculture and Forestry, 23, 383-388. 
Bonaventure, L. (1999). A cultura da cherimóia e de seu híbrido a atemóia. São Paulo: Ed. Nobel.

Chagas, E. A., Barbosa, W., Pio, R., Campo Dall'Orto, F. A., Tizato, L. H. G., Saito, A., Chagas, P. C., \& Scarpare, J. A. F. (2009). Germinação in vitro de gráos de pólen de Prunus persica (L.) Batsch Vulgaris. Bioscience Journal, 25, 8-14.

Chagas, E. A., Pio, R., Chagas, P. C., Pasqual, M., \& Bettiol, J. E., No. (2010). Composiçáo do meio de cultura e condiçóes ambientais para germinação de grãos de pólen de porta-enxertos de pereira. Ciência Rural, 40, 231-266. http://dx.doi.org/10.1590/S010384782010000200002 .

Faria, A. F., Hasegawa, P. N., Chagas, E. A., Pio, R., Purgatto, E., \& Mercadante, A. Z. (2009). Cultivar influence on carotenoid composition of loquats from Brazil. Journal of Food Composition and Analysis, 22, 196-203. http://dx.doi.org/10.1016/j.jfca.2008.10.014.

Ferreira, D. F. (2011). Sisvar: a computer statistical analysis system. Ciência e Agrotecnologia, 35, 1039-1042.

Ferreres, F., Gomes, D., Valentão, P., Gonçalves, R., Pio, R., Chagas, E. A., Seabra, R. M., \& Andrade, P. B. (2009). Improved loquat (Eriobotrya japonica Lindl.) cultivars: Variation of phenolics and antioxidative potential. Food Chemistry, 114, 1019-1027. http:// dx.doi.org/10.1016/j.foodchem.2008.10.065.

Figueiredo, M. A., Pio, R., Silva, T. C., \& Silva, K. N. (2013). Características florais e carpométricas e germinação in vitro de grãos de pólen de cultivares de amoreira-preta. Pesquisa Agropecuária Brasileira, 48, 731-740. http://dx.doi.org/10.1590/S0100-204X2013000700005.

Franchi, G. G., Piotto, B., Nepi, M., Baskin, C. C., Baskin, J. M., \& Pacini, E. (2011). Pollen and seed desiccation tolerance in relation to degree of developmental arrest, dispersal, and survival. Journal of Experimental Botany, 62, 5267-5281. http://dx.doi.org/10.1093/ jxb/err154. PMid:21831844

Franzon, R. C., \& Raseira, M. C. B. (2006). Germinação in vitro e armazenamento do pólen de Eugenia involucrata DC (Myrtaceae). Revista Brasileira de Fruticultura, 28, 18-20. http://dx.doi.org/10.1590/ S0100-29452006000100008.

Gaaliche, B., Majdoub, A., Trad, M., \& Mars, M. (2013). Assessment of pollen viability, germination, and tube growth in eight tunisian caprifig (Ficus carica L.) cultivars. ISRN Agronomy, 2013, 1-4. http:// dx.doi.org/10.1155/2013/207434.
Gaaliche, B., Trad, M., \& Mars, M. (2011). Effect of pollination intensity, frequency and pollen source on fig (Ficus carica L.) productivity and fruit quality. Scientia Horticulturae, 130, 737-742. http://dx.doi. org/10.1016/j.scienta.2011.08.032.

Grassi, A. M., Scarpare, J. A., Fo., Chagas, E. A., Pio, R., Pasqual, M., Tizato, L. G., \& Chagas, P. C. (2011). Qualidade de frutos de cultivares de nespereira em funçáo do ensacamento em diferentes estádios de desenvolvimento. Ciência Rural, 41, 227-229. http:// dx.doi.org/10.1590/S0103-84782011005000003.

Hasegawa, P. N., Faria, A. F., Mercadante, A. Z., Chagas, E. A., Pio, R., Lajolo, F. M., Cordenunsi, B. R., \& Purgatto, E. (2010). Chemical composition of five loquat cultivars planted in Brazil. Ciência e Tecnologia de Alimentos, 30, 552-559. http://dx.doi.org/10.1590/ S0101-20612010000200040.

Nava, G. A., Dalmago, G. A., Bergamaschi, R., \& Marodin, G. A. B. (2009). Fenologia e produção de pessegueiros 'granada' com aplicação de cianamida hidrogenada e boro. Re vista Brasileira de Fruticultura, 31, 297-304. http://dx.doi.org/10.1590/S0100-29452009000200003.

Oliveira, F. L., Dias, V. H. P., Costa, E. M., Filgueira, M. A., \& Espinola, J., So. (2012). Influência das variaçôes climáticas na atividade de vôo das abelhas jandairas Melipona subnitida Ducke (Meliponinae). Revista Ciência Agronômica, 43, 598-603. http:// dx.doi.org/10.1590/S1806-66902012000300024.

Pio, R., Dall'Orto, F. A. C., Barbosa, W., Chagas, E. A., Ojima, M., \& Cia, P. (2007). Produção de cultivares de nespereira na região leste paulista. Pesquisa Agropecuária Brasileira, 42, 1053-1056. http:// dx.doi.org/10.1590/S0100-204X2007000700020.

Ramos, J. D., Pasqual, M., Salles, L. A., Chagas, E. A., \& Pio, R. (2008). Receptividade do estigma e ajuste de protocolo para germinação in vitro de grãos de pólen de citros. Interciencia, 33, 51-55.

Sharafi, Y., Motallebbi-Aza, A. R., \& Bahmani, A. (2011). In vitro pollen germination, pollen tube growth and longevity in some genotypes of loquat (Eriobotria japonica Lindl.). African Journal of Biotechnology, 10, 8064-8069.

Zambon, C. R., Silva, L. F. O., Pio, R., Figueiredo, M. A., \& Silva, K. N. (2014). Estabelecimento de meio de cultura e quantificação da germinaçáo de grãos de pólen de cultivares de marmeleiro. Revista Brasileira de Fruticultura, 36, 400-407. 